\title{
ANÁLISE DE TRONCO DIGITAL: UMA NOVA METODOLOGIA PARA A MEDIÇÃO DE ANÉIS DE CRESCIMENTO
}

\author{
Maria Augusta Doetzer Rosot ${ }^{1}$ \\ Afonso Figueiredo Filho ${ }^{2}$ \\ Attilio Antonio Disperati ${ }^{3}$ \\ Dartagnan Baggio Emerenciano ${ }^{4}$
}

\begin{abstract}
RESUMO
Desenvolveu-se um método digital para medição de anéis de crescimento na análise de tronco, utilizando fotografia digital de fatias, processamento digital de imagens e sistemas de informações geográficas. Trinta fatias de Pinus elliottii, tomadas a diversas alturas no fuste, foram fotografadas com câmera digital ainda na floresta e, depois, transportadas ao laboratório para execução de medição convencional de análise de tronco. $\mathrm{O}$ método digital consistiu na transferência das fotos digitais para o computador, na aplicação de técnicas de realce de contraste e filtragens e da inserção das imagens das fatias em um sistema de informações geográficas. Os polígonos referentes a cada anel foram vetorizados por digitalização em tela e as áreas correspondentes foram estimadas pela aplicação de um fator de escala calculado usando-se a régua fotografada junto a cada fatia. Os volumes por idade estimados pelo procedimento convencional para as duas séries de dados (manual e digital) apresentaram uma diferença média de $7 \%$.

Palavras-chave: fotografia digital, sistema de informações geográficas, área transversal
\end{abstract}

\section{DIGITAL STEM ANALYSIS: A NEW METHODOLOGY FOR MEASURING GROWTH RINGS}

\begin{abstract}
A digital method was developed for the measurement of growth rings in stem analysis using digital photography, digital image processing and geographical information systems. Thirty discs of Pinus elliottii were taken at various heights along the stem and photographed with a digital camera while still at the forest. At the laboratory the discs were measured using the conventional procedure in stem analysis. The digital method consisted of downloading the pictures from the digital camera, applying contrast enhancement techniques and importing images to GIS software, where the polygons corresponding to each ring were drawn through heads-up digitizing. A common ruler photographed in each picture was used to calculate a scale factor, thus allowing the estimation of cross-sectional areas of each growth ring. Volumes per age were estimated using the conventional procedure for both data series (digital and manual) and the average percentage difference between them equaled $7 \%$.
\end{abstract}

Key-words: digital photography, geographical information system, cross-sectional area

\footnotetext{
1 augusta@enpf.embrapa.br, Dra. em Ciências Florestais, Pesquisadora da Embrapa Florestas

2 afig@floresta.ufpr.br, Dr. em Ciências Florestais, Professor do Curso de Engenharia Florestal UNICENTRO e UFPR

3 disperati@avalon.sul.com.br, PhD. em Ciências Florestais, Professor do Curso de Engenharia Florestal UNICENTRO

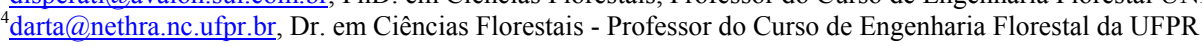

Recebido para publicação: 06/03/2003

Aceito para publicação: 05/08/2003 


\section{INTRODUÇÃO}

A análise de tronco (ANATRO) é uma técnica que possibilita "o registro do crescimento passado de uma árvore" (Husch et al., 1982), mediante a contagem e medição dos anéis de crescimento de seções transversais tomadas a diversas alturas no tronco.

Nagel e Athari (1982) consideram a análise de tronco uma importante fonte de dados para as seguintes linhas de pesquisa:

a) investigação sobre a reação do crescimento em relação a fatores ambientais (bióticos, abióticos) e ao manejo do povoamento (adubação, poda, desbaste);

b) avaliação das alterações de forma das árvores em função dos fatores mencionados no item (a);

c) sincronização das medidas dos anéis de crescimento e determinação do número de anéis ausentes como indicadores do grau de danos sofridos pelas árvores;

d) elaboração de modelos de produção.

Nas empresas florestais a análise de tronco tem sido utilizada, principalmente, para verificação das taxas de incremento médio da floresta, para avaliação da reação do crescimento a tratos culturais ou a determinadas práticas de manejo e para o desenvolvimento de equações de índice de sítio.

Trata-se, no entanto, de um procedimento laborioso, em primeiro lugar pelo trabalho de campo propriamente dito, que envolve a derrubada das árvores, a marcação e o seccionamento das fatias. Em seguida é necessário transportá-las ao laboratório, onde serão secadas e, depois, lixadas para facilitar a visualização dos anéis. $\mathrm{Na}$ última etapa são efetuadas, sobre cada fatia, a marcação e a medição de raios, cujas médias constituem o conjunto de dados gerador de todas as demais informações obtidas na análise de tronco.

Tendo em vista que esses fatores, em conjunto, muitas vezes restringem a aplicação da técnica, tornou-se oportuna a pesquisa de uma metodologia alternativa que eliminasse a fase do transporte do material ao laboratório, a secagem e a preparação das fatias para medição. Para tanto foram utilizadas técnicas fotográficas, adquirindo-se imagens das seções transversais no próprio local de derrubada usando câmera digital e depois processando-as digitalmente para a obtenção de dados de incremento e produção em área transversal.

As imagens obtidas por câmeras fotográficas, sejam elas resultantes de uma perspectiva aérea ou não, podem ser consideradas como produto de técnicas de sensoriamento remoto, uma vez que são adquiridas informações sobre objetos através da análise de dados coletados por instrumentos (sensores) que não estão em contato físico com os objetos em questão (Avery e Berlin, 1992).

A maioria dos sistemas de sensoriamento remoto registra a radiação eletromagnética refletida ou emitida pelo objeto, fenômeno ou área de investigação (Jensen, 1996). A detecção de energia eletromagnética pode ser efetuada fotográfica ou eletronicamente. $\mathrm{O}$ processo da fotografia convencional usa reações químicas na superfície de um filme sensível à luz para detectar as variações de energia numa cena. As vantagens da utilização de filmes incluem o seu baixo custo, relativa simplicidade de uso e integridade geométrica (Lillesand e Kiefer, 1994).

A detecção eletrônica da energia eletromagnética é efetuada através de sensores que geram um sinal elétrico correspondente às variações de energia na cena original (Lillesand e Kiefer, 1994). Os dispositivos eletrônicos responsáveis pela captação da energia são denominados CCDs (charge coupled device dispositivos de carga acoplada) e consistem em um conjunto de células fotossensíveis, encaixadas num chip de silicone, que recebe os fótons da cena. Geralmente é empregado um sistema óptico para coletar, filtrar e focalizar a radiação (Campbell, 1996). Esse é o princípio básico de funcionamento das câmeras digitais, onde o filme no plano focal é substituído por uma matriz de detectores fotossensíveis (CCDs 
de área), num processo conhecido como "fotografia digital" (Lillesand e Kiefer, 1994). Quando a luz atinge a matriz de detectores, cada célula acumula uma carga elétrica proporcional à intensidade da radiação incidente. Uma vez fechado o obturador da câmera, a carga acumulada é transferida, linha a linha, da matriz para um circuito digitalizador (Disperati et al., 2000). O sistema digitalizador é responsável pela conversão analógicodigital (A/D), num processo em que os sinais elétricos originais do sensor são convertidos em informação digital (Marques Filho e Vieira Neto, 1999). Como resultado obtém-se uma matriz bidimensional, onde cada elemento é denominado pixel (picture element) e tem sua posição definida pelos valores de x e y, num sistema de coordenadas "linha, coluna". O brilho ou radiância média medida eletronicamente sobre a área de cada pixel corresponde à sua intensidade e é representada pelo valor de $\mathrm{z}$ ou número digital (DN - digital number) ou, ainda, nível de cinza.

Os CCDs apresentam resposta linear a intensidade de brilho, de forma que as imagens produzidas com o uso desses dispositivos possuem uma relação mais consistente com a amplitude de radiância que emana do objeto considerado quando comparadas às imagens obtidas por processos fotográficos convencionais (Campbell, 1996).

No manejo florestal e, por conseguinte, na dendrometria, a combinação de técnicas de sensoriamento remoto e de processamento digital de imagens vem acompanhando uma tendência mundial no sentido de se aumentar a rapidez e a precisão na obtenção e processamento de dados, principalmente com o uso de geotecnologias.

Yanosky e Robinove (1986) foram os pioneiros na utilização de software de processamento de imagens de satélite.para medir a área e estruturas anatômicas de anéis de crescimento usando vetorização em tela.

Thetford et al. (1991) desenvolveram um sistema para a medição de anéis de crescimento em estudos dendrocronológicos, que determinava, ao mesmo tempo, a densidade e a largura dos anéis. O programa, denominado Macdruid, detectava automaticamente os limites dos anéis de crescimento e permitia ao usuário corrigir eventuais erros de delimitação.

Técnicas de análise de imagem aplicadas à análise de tronco foram empregadas por Tasissa e Burkhart (1997) para estudar as variações verticais e laterais na largura média dos anéis de crescimento de árvores de Pinus taeda submetidas a diferentes intensidades de desbaste.

No Brasil, Rigozo e Nordemann (2000) vêm desenvolvendo um novo método interativo de análise de imagens para determinar a espessura dos anéis de crescimento. $\mathrm{O}$ sistema utiliza um computador, um scanner de alta resolução para adquirir as imagens das fatias em formato digital e um programa desenvolvido no ambiente IDL 5.0 $(\mathrm{ENVI})^{5}$, que lê e realça as imagens. A delimitação dos anéis ao longo do raio selecionado é efetuada pelo operador com auxílio do mouse. O programa calcula, então, a largura dos anéis, gerando um gráfico com as posições de cada anel em função da distância da medula e dos níveis de cinza da imagem. Também é criado um arquivo de dados contendo a série temporal das espessuras dos anéis. Em se tratando de anéis muito estreitos, recomendam empregar resoluções de 900 dpi a 1200 dpi durante o processo de escanerização.

Rosot et al. $(2000,2001)$ utilizaram a imagem escanerizada de uma fatia de Araucaria angustifolia (Bert.) O. Ktze. para testar a viabilidade do uso de técnicas de análise de imagem na estimativa de áreas transversais. As áreas "reais" correspondentes aos anéis foram obtidas por planimetria eletrônica, com precisão de $1 \mathrm{~mm} 2$. Além disso, foram medidos raios eqüidistantes sobre a fatia (séries de 4 e 8 raios), conforme procedimento usual em análise de tronco, com a finalidade de comparar os resultados com aqueles obtidos por planimetria e por técnicas de análise de

\footnotetext{
${ }^{5}$ IDL (ENVI) - Interactive Data Language (The Environment for Visualizing Images - Research Systems Inc.)
} 
imagem. Foi empregado o software SPRING $^{6}$, importando-se a imagem para o projeto e submetendo-a a técnicas de realce de contraste com o objetivo de melhorar sua qualidade. A individualização dos anéis foi efetuada mediante vetorização em tela, utilizando-se o mouse para definir os limites dos anéis, tendo como fundo a imagem da fatia. Procedeu-se, então, ao ajuste e poligonalização das linhas criadas e à posterior associação de cada polígono a um determinado anel de crescimento. O tratamento dos anéis como objetos de um mapa cadastral permitiu a obtenção de suas áreas individuais e a utilização do módulo de consulta a objetos, o que, por sua vez, possibilitou a exportação dos resultados em forma tabular para outro aplicativo e a posterior obtenção da produção e incremento em área transversal a cada idade. A realização do teste $t$ para amostras emparelhadas permitiu concluir que, a um nível $\alpha$ de probabilidade igual a 0,05 , não existe diferença significativa entre áreas obtidas por planimetria e por técnicas de análise de imagem. As diferenças entre as áreas transversais estimadas pelo SPRING e as "reais" situaram-se, em média, em torno de $0,25 \%$ por anel, oscilando entre um mínimo de $-0,01 \%$ e um máximo inferior a $2,4 \%$.

Biging e Wensel (1984) descrevem uma técnica fotográfica para análise de tronco de coníferas da Califórnia - E.U.A., onde foi empregada uma câmera fotográfica $35 \mathrm{~mm}$ e filme colorido para fotografar as fatias no campo, logo após a derrubada das árvores. Utilizando a função digitalizadora de um microdensitômetro, as transparências fotográficas foram escanerizadas a uma resolução de $0,00127 \mathrm{~mm}$. A imagem foi projetada em tela com aumento de 20 vezes e, através do cursor, o operador determinava os limites dos anéis, cujas coordenadas cartesianas eram gravadas em fita magnética. Os autores citam como vantagem do emprego da técnica fotográfica a redução de tempo na coleta dos dados, a eliminação da necessidade de transporte de grandes quantidades de

\footnotetext{
${ }^{6}$ SPRING - Sistema de Processamento de Informações Georreferenciadas (INPE)
}

material ao laboratório e a diminuição de problemas associados à contração radial das fatias. A restrição quanto à utilização deste método está relacionada ao equipamento usado (microdensitômetro), desenvolvido pelo Laboratório de Ciências Espaciais da Universidade de Berkeley - Califórnia.

Goelz e Burk (1987) empregaram técnica fotográfica semelhante à de Biging e Wensel (1984), porém utilizando equipamento mais acessível a pesquisadores florestais. Também utilizaram câmeras $35 \mathrm{~mm}$ para fotografar fatias de Picea glauca e Abies balsamea, com filme colorido e preto e branco, porém não no campo, mas, sim, sob casa de vegetação e tenda de sombreamento, que, em conjunto, permitiam a passagem de $11 \%$ da luz incidente, aproximando-se, assim, das condições de luminosidade na floresta. Foi escolhido um raio aleatório, marcado de forma permanente nas fatias. A distância radial entre o câmbio e cada anel de crescimento foi medida manualmente utilizando microscópio binocular e régua com precisão de $0,02 \mathrm{~cm}$. A medição manual e o procedimento fotográfico foram repetidos depois que a região da fatia contendo o raio selecionado foi aplainada. As cópias impressas $(8,9 \mathrm{~cm} \mathrm{X} \mathrm{12,7} \mathrm{cm)}$ das fotografias foram digitalizadas via mesa digitalizadora com resolução de 0,00254 $\mathrm{cm}$. Empregou-se um programa em linguagem BASIC para converter as coordenadas cartesianas em incrementos correntes anuais. Concluíram que fotografias em preto e branco de fatias nãoaplainadas são uma alternativa satisfatória ao transporte das seções ao laboratório, pois as medições utilizando este método não diferiram significativamente daquelas obtidas manualmente.

O objetivo geral do presente trabalho foi desenvolver e analisar procedimentos de obtenção de dados de área transversal para a análise de tronco usando técnicas fotográficas associadas a processamento digital de imagens $\mathrm{e}$ sistemas de informações geográficas (SIG). 


\section{MATERIAIS E MÉTODOS}

A árvore-amostra utilizada no processo de definição da nova metodologia foi selecionada em um povoamento de Pinus elliottii Engelm. de 17 anos, localizado em Colombo-PR e pertencente à Embrapa Florestas. Primeiramente foram obtidas imagens com câmera digital das fatias tomadas a diversas alturas no fuste e, depois, as fatias foram transportadas ao laboratório para medição manual da largura dos anéis de crescimento.

\section{Coleta de dados em campo}

Uma vez selecionada a árvore foram efetuadas marcas horizontais no fuste a 1,30 m e uma marca vertical indicando a direção norte. Procedeu-se, então, à derrubada com motosserra e posterior desgalhamento. Com auxílio de uma trena e fazendo-se coincidir a marca de $1,30 \mathrm{~m}$ com o traço horizontal no fuste, foi medida a altura total da árvore.

As fatias foram coletadas a $0,0 \mathrm{~m}$; $0,3 \mathrm{~m} ; 0,7 \mathrm{~m} ; 1,3 \mathrm{~m}$ e de 1 em 1 metro ou entre os verticilos ao longo do fuste até a altura total. A direção Norte também foi marcada nos discos para, posteriormente, organizar as fatias com a mesma orientação em relação umas às outras.

Após o corte, a superfície das fatias foi escovada com álcool com a finalidade de remover resíduos de serragem, sujeira e excesso de resina. Em seguida cada fatia foi colocada sobre a plataforma de um tripé, recebendo uma etiqueta auto-adesiva para identificação, colada na porção da casca, onde constavam o número da árvore e da seção. Junto à fatia foi colocada uma escala, fazendo-se coincidir o plano da régua com o plano da superfície da fatia.

Ainda na floresta cada fatia foi fotografada com uma câmera digital da marca Sony, modelo DSC-S85, CCD de 4,1
Megapixel, resolução máxima de 2272 colunas por 1704 linhas, acoplada ao tripé e equipada com objetiva de lentes Carl Zeiss, de distância focal variando de 34 a $102 \mathrm{~mm}$ em escala equivalente à das câmeras convencionais. Foi selecionado o modo "fine", que permite a obtenção de fotos com resolução máxima, em formato JPEG, que apresenta boa taxa de compressão, conseqüentemente reduzindo o tamanho dos arquivos.

Em seguida cada fatia foi identificada com o número da árvore e a altura da seção, na face inferior. Os dados complementares, como CAP, altura total e altura das seções, foram devidamente registrados em formulário apropriado. $\mathrm{O}$ acondicionamento, para posterior transporte ao laboratório, foi efetuado em sacos de estopa por permitirem boa ventilação.

\section{Medição convencional}

No laboratório todas as fatias foram colocadas para secagem em estufa a aproximadamente $70^{\circ} \mathrm{C}$, em pé, com espaço suficiente entre si para permitir uma boa circulação de ar, até secagem adequada. Em seguida a face de medição foi lixada em máquina, inicialmente com lixas mais grossas (número 80) e, depois, progressivamente, com lixas mais finas até a lixa número 200.

Determinou-se, então, o maior raio de cada fatia colocando-se a ponta seca de um compasso sobre a medula. A localização desse raio foi marcada com lápis sobre a face de medição. Prolongandoo em linha reta sobre a medula, marcou-se outro raio e, em seguida, mais dois, perpendiculares a este. Usando-se régua comum (fig. 1) foram medidos os comprimentos dos raios e a sua média inserida na fórmula da área do círculo forneceu as estimativas de áreas transversais correspondentes a cada anel. 


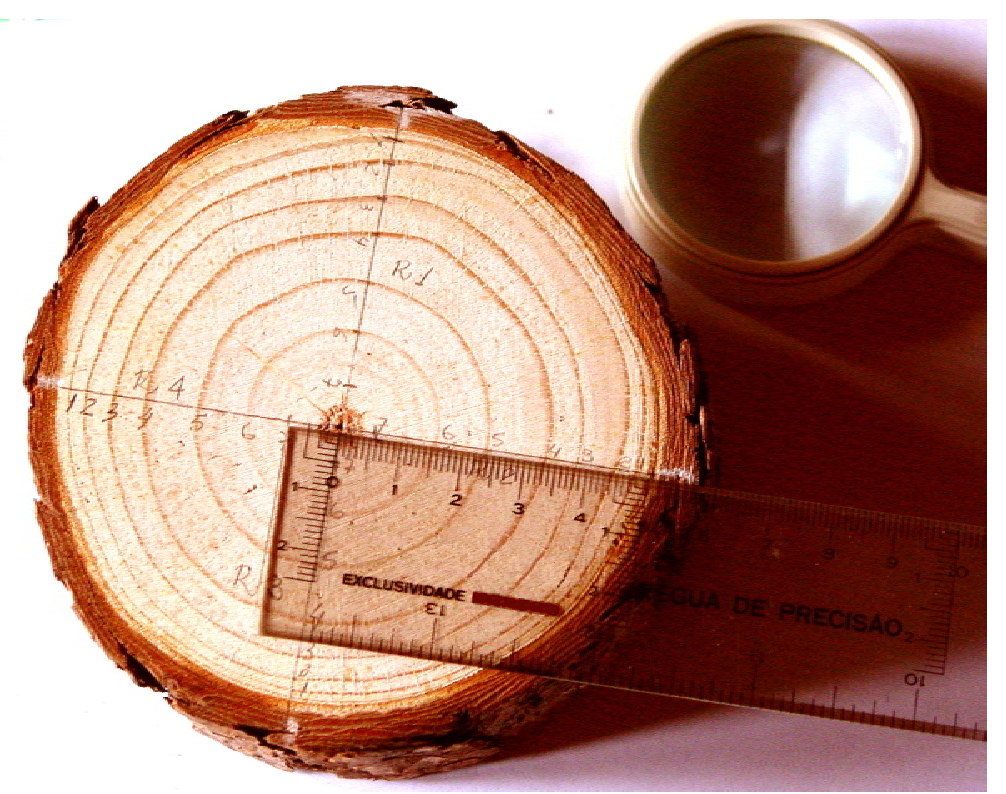

Figura 1: Medição manual de raios sobre a fatia seca e lixada

Figure 1: Manual measurement of radii on the dry and sanded disc

Os raios médios foram usados, também, para se estimar as alturas totais a cada idade com base no método do paralelismo ao anel imediatamente anterior (Barusso, 1977), cujo desenho diagramático é apresentado na Figura 2:

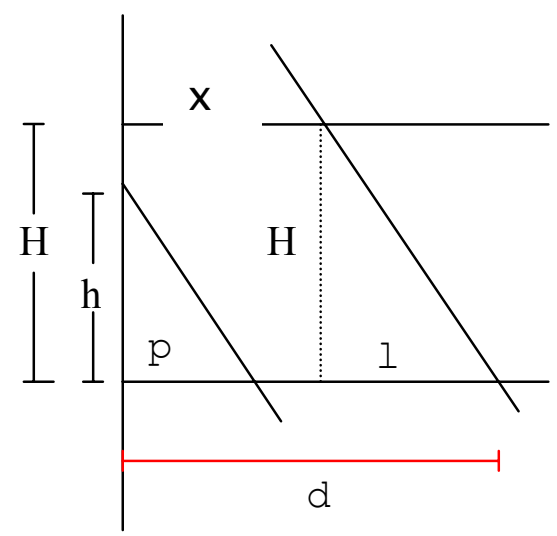

$$
\begin{aligned}
& \frac{h}{H}=\frac{\mathrm{p}}{\mathrm{l}} \\
& \mathrm{l}=\mathrm{d}-\mathrm{x} \\
& \mathrm{h}=\frac{\mathrm{p} \times \mathrm{H}}{\mathrm{l}}
\end{aligned}
$$

Figura 2: Diagrama do método do paralelismo para interpolação da altura total da árvore a uma determinada idade

Figure 2: Diagrammatic representation of the method of paralelism for interpolating the total tree height at a given age

Onde:

$\mathrm{H}=$ comprimento da seção

$\mathrm{h}=$ altura do término do anel

$\mathrm{d}=$ comprimento do penúltimo

raio da fatia inferior

$\mathrm{p}=$ comprimento do último raio da fatia inferior

$\mathrm{x}=$ comprimento do último raio

da fatia superior
A altura total da árvore na idade correspondente ao anel foi obtida somandose a altura de tomada da fatia inferior à altura estimada do término do anel.

Os volumes das seções foram calculados pelo método de Smalian e a sua somatória forneceu o volume total sem casca a cada idade. 


\section{Processamento digital de imagens}

A transferência dos arquivos de imagem da câmera digital para o computador foi efetuada através de cabo e porta USB, segundo o procedimento usual para descarregamento de imagens digitais empregando-se o software Adobe Photoshop.

Todas as imagens das fatias foram submetidas a técnicas de realce de contraste e brilho para o aumento da nitidez. Os software de processamento de imagens empregados - Adobe Photoshop e Microsoft PhotoEditor - permitiram a manipulação interativa das imagens digitais quanto a características como cor, brilho, contraste e intensidade.

As imagens que possuem baixo contraste concentram a maioria dos seus DNs em uma estreita faixa da escala de cinza (Marques Filho e Vieira Neto, 1999). Assim, a finalidade do aumento de contraste é redistribuir os níveis de cinza (DNs) de modo a expandir sua amplitude dentro do intervalo radiométrico considerado.

A modificação do histograma de freqüência de uma imagem implica na utilização de uma função de transferência de contraste, geralmente apresentada como uma curva plotada em relação aos eixos que representam a imagem original e a modificada (Crósta, 1993). Com a utilização do software Adobe Photoshop foi possível manipular essa curva, alterando, com isso, a função de transferência e, conseqüentemente, os DNs e respectivas freqüências na nova imagem.

$\mathrm{O}$ realce de imagens no domínio espacial, efetivado através da aplicação de filtros denominados "passa-alta", tem por objetivo destacar detalhes finos na imagem (Marques Filho e Vieira Neto, 1999). Sendo a nitidez uma característica fundamental para a discriminação dos anéis de crescimento, as imagens das fatias foram submetidas a efeitos de sharpening ou "foco", que consistem na aplicação de "máscaras" quadradas, formadas por coeficientes positivos nas proximidades de seu centro e negativos longe dele (Marques Filho e Vieira Neto, 1999), que se deslocam sobre a matriz dos dados originais, multiplicando os valores dos DNs.

Nesta pesquisa adotou-se a metodologia proposta por Tucker e Chakraborty (1997) para a medição das áreas transversais dos anéis de crescimento. $\mathrm{O}$ método, denominado "software planimeter", consiste em digitalizar uma linha ao redor do objeto de interesse na imagem mostrada na tela e obter sua área, calculada automaticamente pelo software através de fórmulas de álgebra linear, usando as coordenadas dos polígonos. Moreira (2001) comenta que este procedimento minimiza muitos erros de omissão e de inclusão de áreas, normalmente observados em outros métodos de cálculos de área como rede de pontos, pesagem ou planimetragem.

Para a medição de áreas elegeu-se o software ArcView GIS, versão 3.1, desenvolvido pelo Environmental Systems Research Institute (ESRI), que permite a visualização, consulta e análise espacial de dados. Embora direcionado a aplicações geo-ambientais e manipulação de dados com referência geográfica, o programa é aplicável, na verdade, a quaisquer projetos contendo entidades gráficas que possuam localização espacial, mesmo que relativa, como é o caso dos anéis de crescimento na fatia.

A estrutura de processamento de dados no ArcView é orientada a objetos, sendo que o programa incorpora o conceito de "documentos", que possuem uma interface gráfica própria e são utilizados na execução de tarefas específicas (SENAGRO, 2002). Assim, as "Vistas" permitem a visualização, consulta e análise de dados espaciais e imagens; as "Tabelas" apresentam dados tabulares; os "Gráficos" possibilitam o desenho e visualização de gráficos; os "Lay-outs" geram os produtos para impressão e os "Scripts" contêm os programas em linguagem Avenue (linguagem proprietária do ArcView) para a execução de determinados processamentos.

As "Vistas" contêm os "Temas" também conhecidos como "shapes" devido ao formato "shapefile" dos arquivos vetoriais do ArcView - que são compostos por feições que representam a ocorrência de 
determinado objeto no terreno através de primitivas gráficas como ponto, linha, polígonos e textos correspondentes à toponímia.

Após as imagens terem sido submetidas a procedimentos de realce de contraste e filtragem espacial, foi utilizado o comando "rotate" (Rotacionar) do software Adobe Photoshop, "girando-se" as fatias para que todas apresentassem a mesma orientação (exposição Norte) em relação ao eixo vertical da imagem, marcada na casca com lápis vermelho por ocasião da coleta. Em seguida todas as imagens JPEG foram importadas pelo software ArcView, onde se procedeu à vetorização dos limites dos anéis de crescimento, representados por entidades do tipo polígono. Dessa forma cada "Tema" (fatia) era composto por tantas feições quanto $o$ número de anéis. Automaticamente era gerada uma tabela de atributos com o tipo de feição e uma coluna para identificação do polígono, que foi preenchida com os respectivos números dos anéis.

O comando "Returnarea" (retornar a área) aplicado, na tabela, à coluna que contem o tipo de feição, permitiu calcular automaticamente a área de cada polígono. Considerando que não foi efetuada previamente nenhuma operação de registro e transformação de escala às imagens das fatias, foi necessário aplicar um fator de correção para a obtenção das áreas em centímetros quadrados. Esse fator foi estimado a partir da escala fotografada junto à fatia. Após o cálculo das áreas transversais empregou-se o comando "Calculate" (Calcular), que possibilita operações entre as colunas da tabela, para calcular o raio médio correspondente a cada anel.

$\mathrm{Na}$ tabela de atributos de cada tema (fatia) foram inseridos campos adicionais, tais como número do talhão, da árvore e da fatia, data da coleta, CAP, altura total, gênero, espécie, altura da seção e observações. Estando em formato DBF, essa tabela pôde, então, ser facilmente incorporada à planilha eletrônica Microsoft Excel onde foram executados os mesmos cálculos referentes à medição manual: a) altura total a cada idade pelo método do paralelismo usando os raios médios (Barusso, 1977);

b) volume da seção (método Smalian);

c) volume total por idade.

\section{Análise estatística}

Os volumes por idade obtidos pelos dois métodos foram comparados por meio de um teste $t$ emparelhado, que é utilizado quando as observações de duas populações de interesse - no caso as estimativas de volume a partir de ANATRO digital e manual - são coletadas em pares (para a mesma idade, para cada método), obtendose, assim, amostras denominadas dependentes ou emparelhadas. $O$ teste da hipótese $\mathrm{H} 0$ de que a média da distribuição das diferenças $(\mu \mathrm{D})$ entre um e outro método de medição é igual a zero baseia-se na estatística de teste $\mathrm{t}$ (Werkema, 1996):

$$
\begin{aligned}
& \mathrm{t}_{\mathrm{o}}=\frac{\bar{D}}{s_{D} / \sqrt{n}}, \quad \text { em que: } \\
& \bar{D}=\frac{1}{n} \sum_{i=1}^{n} D_{i} \quad \text { é a média da }
\end{aligned}
$$

amostra das diferenças;

$$
s_{\bar{D}}{ }^{2}=\frac{1}{n-1} \sum_{i=1}^{n}\left(D_{i}-\bar{D}\right)^{2} \quad \text { é } \quad \text { a }
$$

variância da amostra das diferenças;

$\mathrm{D}_{\mathrm{i}}=$ diferença entre o volume manual e digital, para a idade $\mathbf{i}$;

$\mathrm{n}=$ tamanho da amostra das diferenças. rejeitada se:

A hipótese $\mathrm{H}_{0}: \mu_{\mathrm{D}}=0$ deverá ser

$$
\mathrm{t}_{\mathrm{o}}>\mathrm{t}_{\alpha / 2 ; \mathrm{n}-1} \text { ou } \mathrm{t}_{\mathrm{o}}<-\mathrm{t}_{\alpha / 2 ; \mathrm{n}-1}
$$

\section{RESULTADOS E DISCUSSÃO}

\section{Utilização de fotos digitais na coleta de dados para ANATRO}

A diferença entre o procedimento convencional de coleta de dados para análise de tronco e a metodologia adotada nesta pesquisa foi a tomada de fotos digitais das fatias ainda na floresta. A adoção de 
algumas medidas de ordem prática foi importante para a obtenção de fotografias de boa qualidade. Entre elas pode-se citar:

a) o uso de motosserra com sabre de tamanho apropriado e corrente nova para evitar a formação de "marcas" sobre a face da fatia a ser fotografada;

b) a limpeza das fatias com escova e álcool para a remoção do excesso de resina e outros resíduos (especialmente para a espécie considerada - Pinus elliottii);

c) a fixação da máquina fotográfica em tripé e, se possível, utilização de tripé especial com base, para nivelamento da fatia.

Empregando-se a câmera digital foi possível verificar a qualidade e resolução de cada fotografia através dos recursos de ampliação oferecidos pela máquina. As raras fotos que apresentaram problemas de foco ou iluminação inadequada foram excluídas e, nesses casos, a fatia em questão pôde ser fotografada novamente.

O formato JPEG e a resolução de 1704 linhas por 2272 colunas, adotados nesta pesquisa, permitiram que fossem armazenadas até 32 imagens em um cartão de memória de 64 Megabytes. Assim foi possível gravar as imagens das 30 fatias em apenas um cartão, com arquivos variando de 0,6 a 3 Megabytes de tamanho. Numa situação real de análise de tronco deve-se prever a necessidade de cartões com maior capacidade (128 ou 256 Megabytes). Alternativamente, é possível transferir as imagens do cartão de memória para o disco rígido de um computador portátil, do tipo laptop, sempre que a capacidade de armazenamento se tenha esgotado.

Considera-se que a eliminação da necessidade do transporte das fatias ao laboratório, bem como da secagem e aplicação de lixas, constitui a principal vantagem do emprego de técnicas fotográficas nos procedimentos de análise de tronco. Um segundo aspecto a ser levado em consideração é a significativa redução do espaço físico necessário para o armazenamento dos dados, pois tanto as imagens das fatias como os resultados das medições passam a ser arquivados em meio digital (CD-ROM, HD, Zip-disk, etc).

$\mathrm{O}$ custo do equipamento digital ainda levado - tende a diminuir com a sua gradativa popularização no mercado. A praticidade de uso e a facilidade no manuseio - observadas tanto para a tomada das fotos como na transferência dos arquivos para o computador - fizeram com que se considerasse a câmera digital um instrumento adequado e eficaz para a coleta de dados em ANATRO.

\section{Processamento digital de imagens}

As fotos digitais mesmo antes de qualquer tratamento já apresentaram grande riqueza de detalhes e boa discriminação entre lenho primaveril e outonal.

Os realces de contraste e filtragens aplicados sobre as imagens aumentaram a nitidez e facilitaram a delimitação dos anéis de crescimento especialmente nas fatias das porções inferiores do fuste, onde os anéis eram mais numerosos e mais estreitos.

Em geral a delimitação dos anéis no software ArcView foi efetuada sem dificuldades, excetuando-se aquelas fatias que apresentaram anéis muito estreitos na região próxima à casca.

Uma das maiores vantagens apresentada pela digitalização em tela foi a possibilidade da aplicação do recurso de ampliação (zoom) para a discriminação do limite dos anéis (fig. 3). No entanto, observou-se que, freqüentemente, é necessário estabelecer um compromisso entre um tamanho de pixel grande o suficiente para se definir com precisão o limite entre lenho outonal e primaveril, porém pequeno o suficiente para que se possa acompanhar a trajetória do anel. 


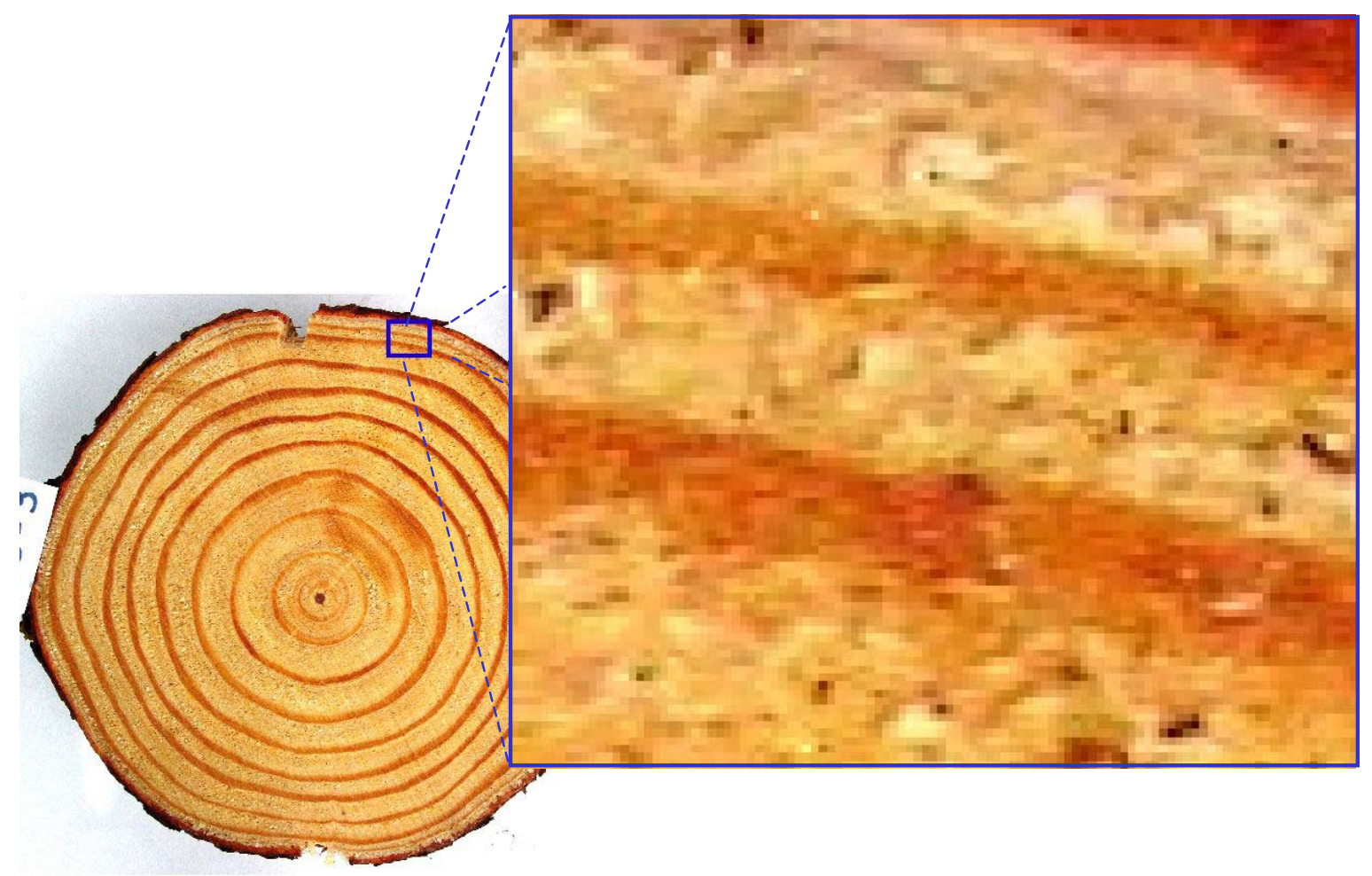

Figura 3: Foto digital de uma fatia inteira e detalhe da ampliação dos anéis

Figure 3: Digital picture of a whole disc and zoomed growth rings

A discriminação dos anéis baseouse em características tais como cor, textura, forma e tamanho associadas a informações de contexto. Em analogia às práticas comuns do geoprocessamento, o processo de delimitação dos anéis de crescimento assemelhou-se a uma interpretação visual de imagem associada ao procedimento de vetorização propriamente dito. Embora a técnica aplicada possa ser considerada como de fácil aprendizagem, é necessário reconhecer que a experiência do operador é um fator importante para o sucesso do método, contribuindo para isso o gradativo aumento da capacidade do analista em reconhecer padrões.

O comando "Vertex Edit" (editar vértices) possibilitou a edição dos polígonos digitalizados. Os pontos adquiridos durante a digitalização puderam ser facilmente excluídos ou movidos para outro local e novos pontos foram acrescentados quando necessário. É relevante observar que todas as operações de edição de feições devem ser efetuadas antes do cálculo de área, pois alterações posteriores não refletem atualizações em áreas já calculadas.

À "Vista" criada no software ArcView para a visualização das imagens foram adicionados os 30 "Temas" correspondentes às 30 fatias coletadas para a análise. Como todas as imagens JPEG foram importadas para a mesma localização espacial não foi possível visualizá-las simultaneamente. No entanto, isso não prejudicou a vetorização dos anéis uma vez que os procedimentos foram efetuados para cada fatia separadamente.

À medida que cada anel era digitalizado, o campo "ID" da tabela de atributos era preenchido com o respectivo número do anel. Os demais campos de cabeçalho (fig. 4), tais como número da árvore, data de coleta, CAP, foram acrescentados à tabela através do comando 
"Edit - Add field" (Editar - adicionar campo) e foram preenchidos usando-se o comando "Calculate" (calcular), acessado a partir do menu "Field" (campo). O fator de escala médio para cada fatia, obtido através da ferramenta "Measure" (medir), também foi inserido na tabela dessa maneira.

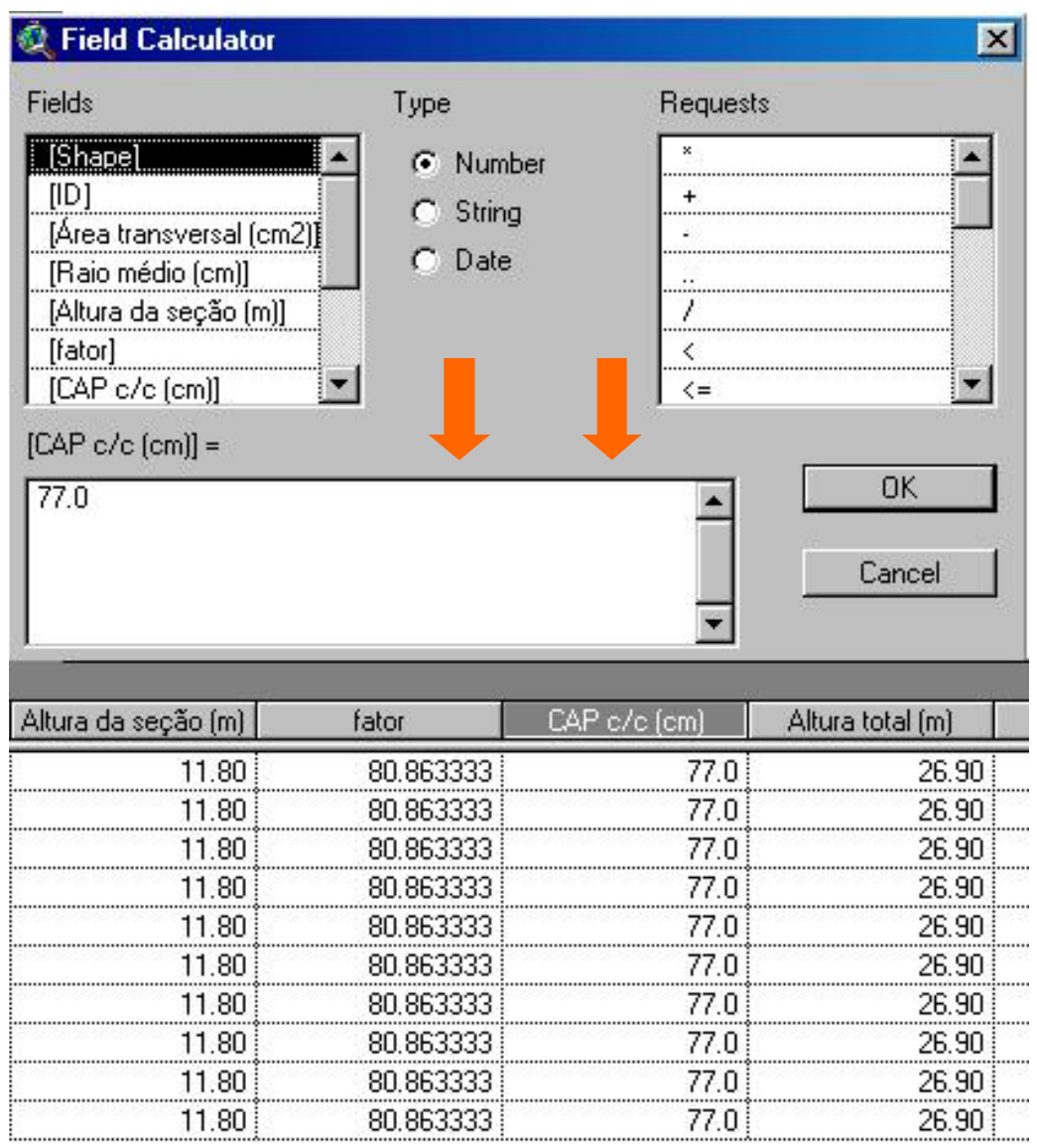

Figura 4: Janela do software ArcView mostrando o preenchimento da tabela de atributos Figure 4: ArcView's window showing editing operations performed on the attribute table

A construção da expressão mostrada na Figura 5 permitiu calcular o raio médio correspondente à área transversal de cada anel. A função ".Sqrt" (raiz quadrada) foi inserida a partir da lista de expressões disponíveis no menu. 


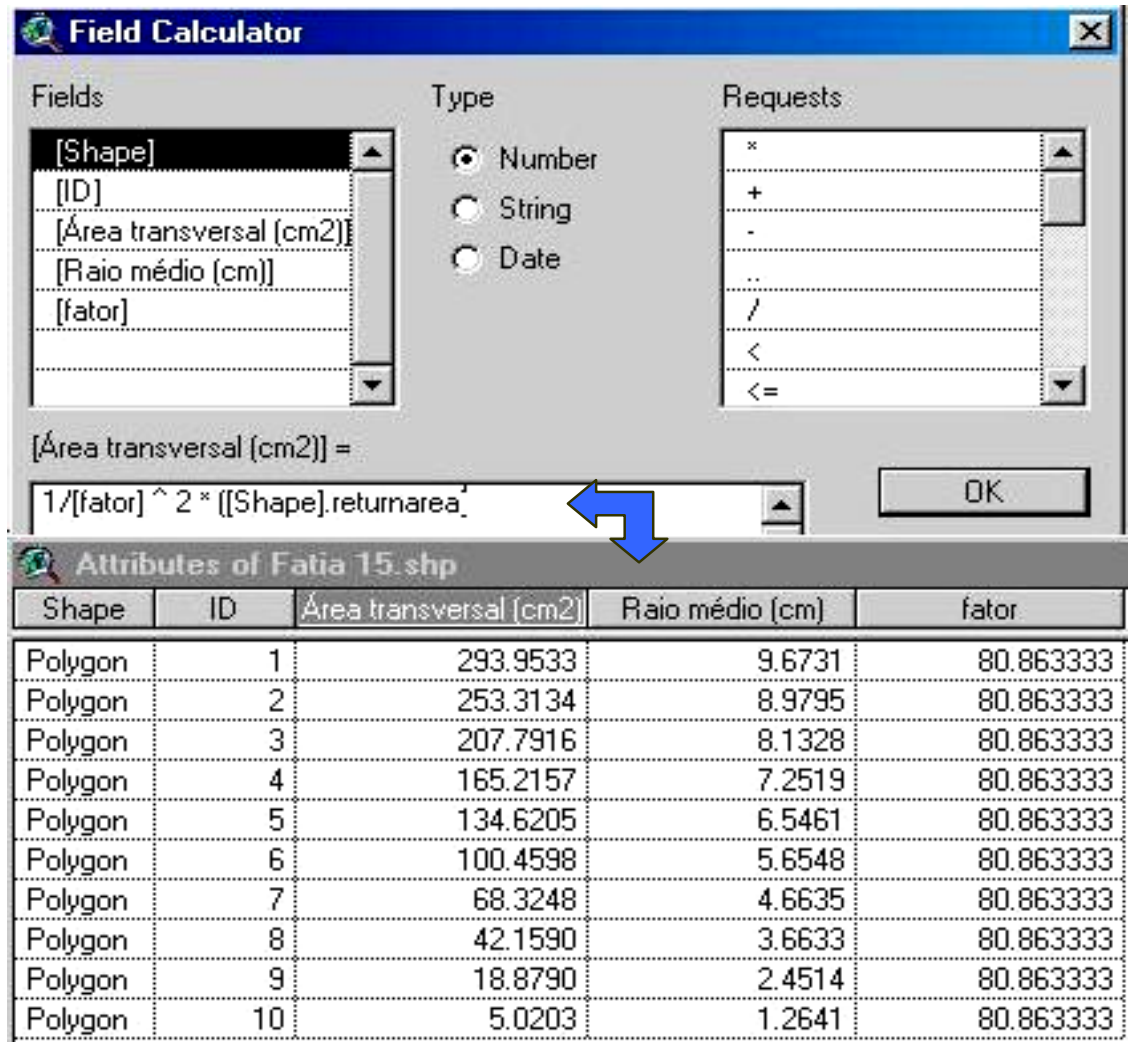

(a)

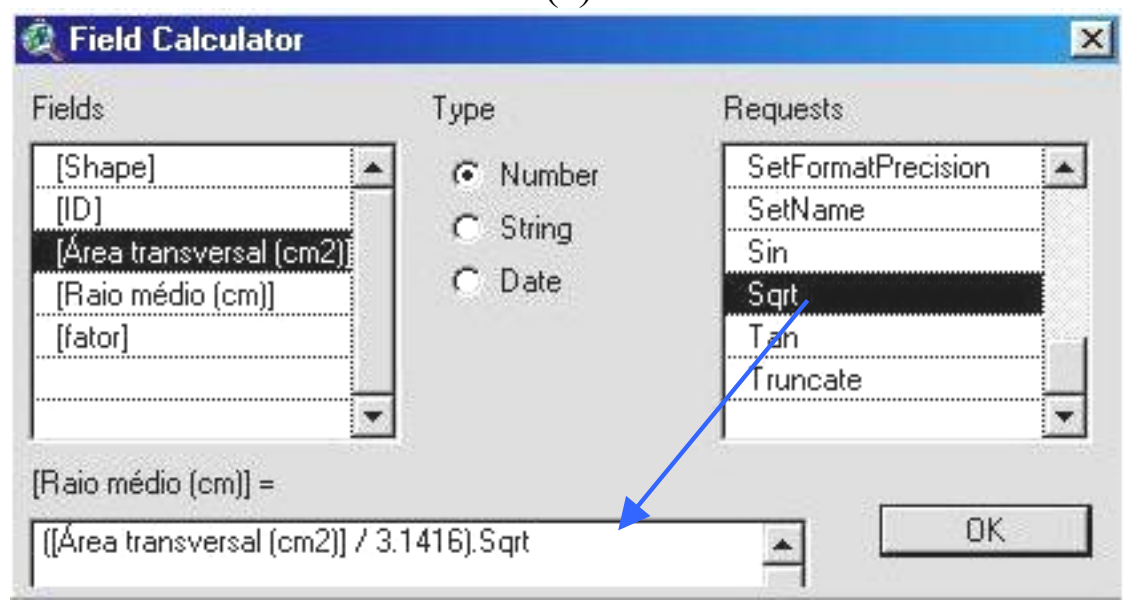

(b)

Figura 5: Janela do software ArcView mostrando o cálculo de área transversal (a) e raio médio (b)

Figure 5: ArcView's window showing the calculation of cross-sectional areas (a) and average radius (b)

$\mathrm{Na}$ Figura 6 é apresentada uma vista geral da janela de trabalho no software ArcView contendo a imagem JPEG adquirida com câmera digital e, sobrepostos a ela, os anéis de crescimento vetorizados por digitalização via tela. Na parte superior da janela pode-se visualizar uma parte da tabela dos atributos alfa-numéricos correspondentes ao tema (fatia). 


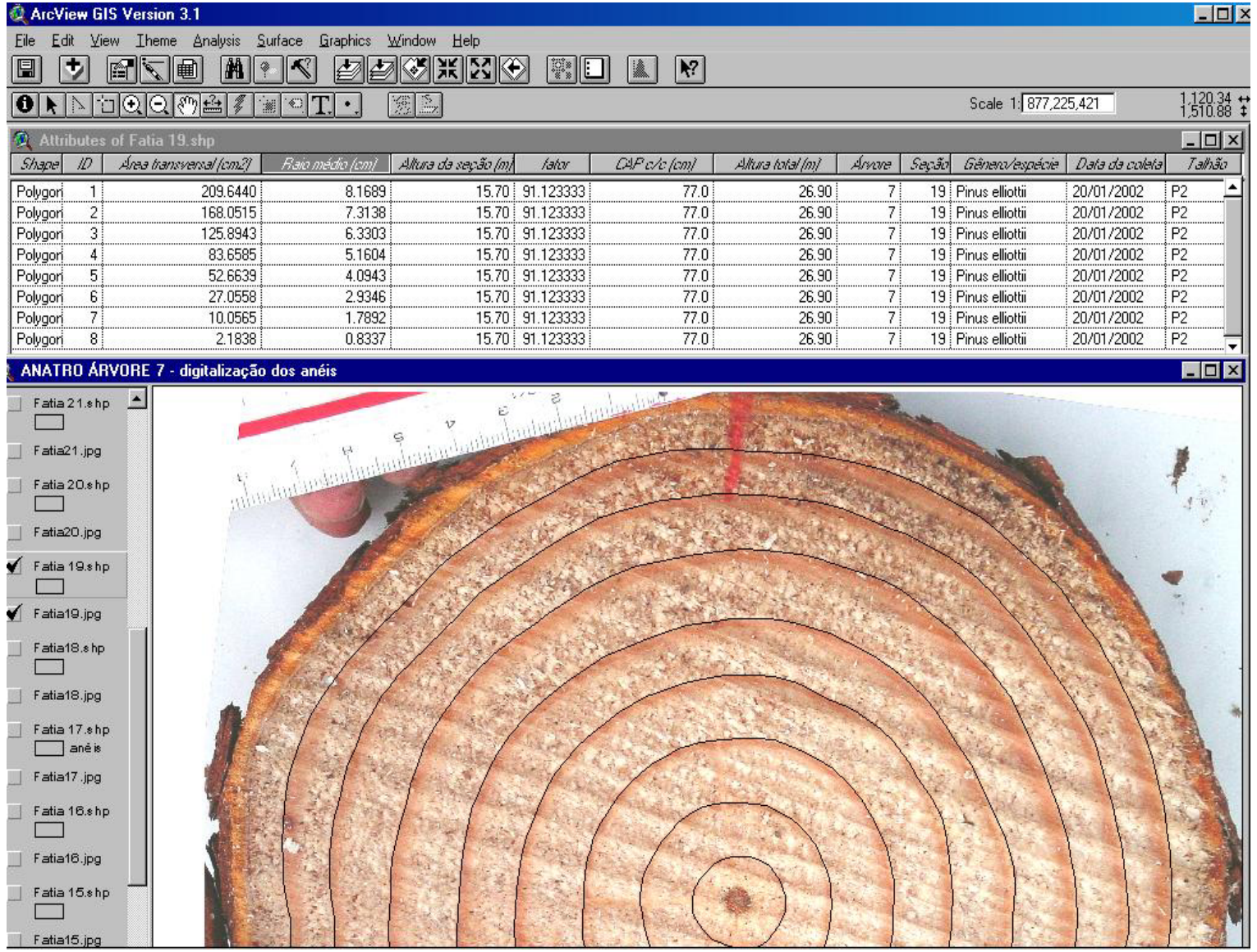

Figura 6: Janela do software ArcView com a imagem da fatia, "shape" dos anéis e respectiva tabela de atributos

Figure 6: ArcView's window showing the disc, the rings "shapes" and their respective attribute table

A visualização padrão adotada para a ANATRO digital foi a de polígonos vazados, sendo exibido apenas seu contorno, em preto. No entanto, a representação de polígonos "cheios", preenchidos com cores, pode ser utilizada para realçar aspectos como a forma e a área dos anéis de crescimento. Uma vantagem adicional desse tipo de representação é o destaque colorido dado aos polígonos (anéis) selecionados por consulta ao banco de dados.

$\mathrm{Na}$ Figura 7 é apresentada a imagem da fatia coletada a 13,6 m de altura e, sobre ela, os polígonos correspondentes aos anéis. Nesse caso utilizou-se a opção "Unique value" (valor exclusivo) na paleta de símbolos, selecionando-se o campo "código" (número) do anel para a atribuição de cores.
Ao mesmo tempo efetuou-se uma consulta por atributos, desejando-se saber quais os anéis de crescimento que apresentavam área transversal entre $50 \mathrm{e}$ $100 \mathrm{~cm} 2$. Para isso empregou-se a ferramenta "Query builder" (construtor de consultas), que aciona a abertura de uma caixa de diálogo como a que aparece no canto superior direito da Figura 6. No caso deste exemplo foi construída a seguinte expressão:

( [Área transversal] $>=50)$ and ( [Área transversal] $<=100$ )

Os anéis 5 e 6, com áreas transversais iguais a 61,8 e $93,0 \mathrm{~cm} 2$, respectivamente, corresponderam aos quesitos da consulta, sendo realçados em amarelo tanto na imagem como na tabela de atributos (fig. 7, embaixo, à direita). 


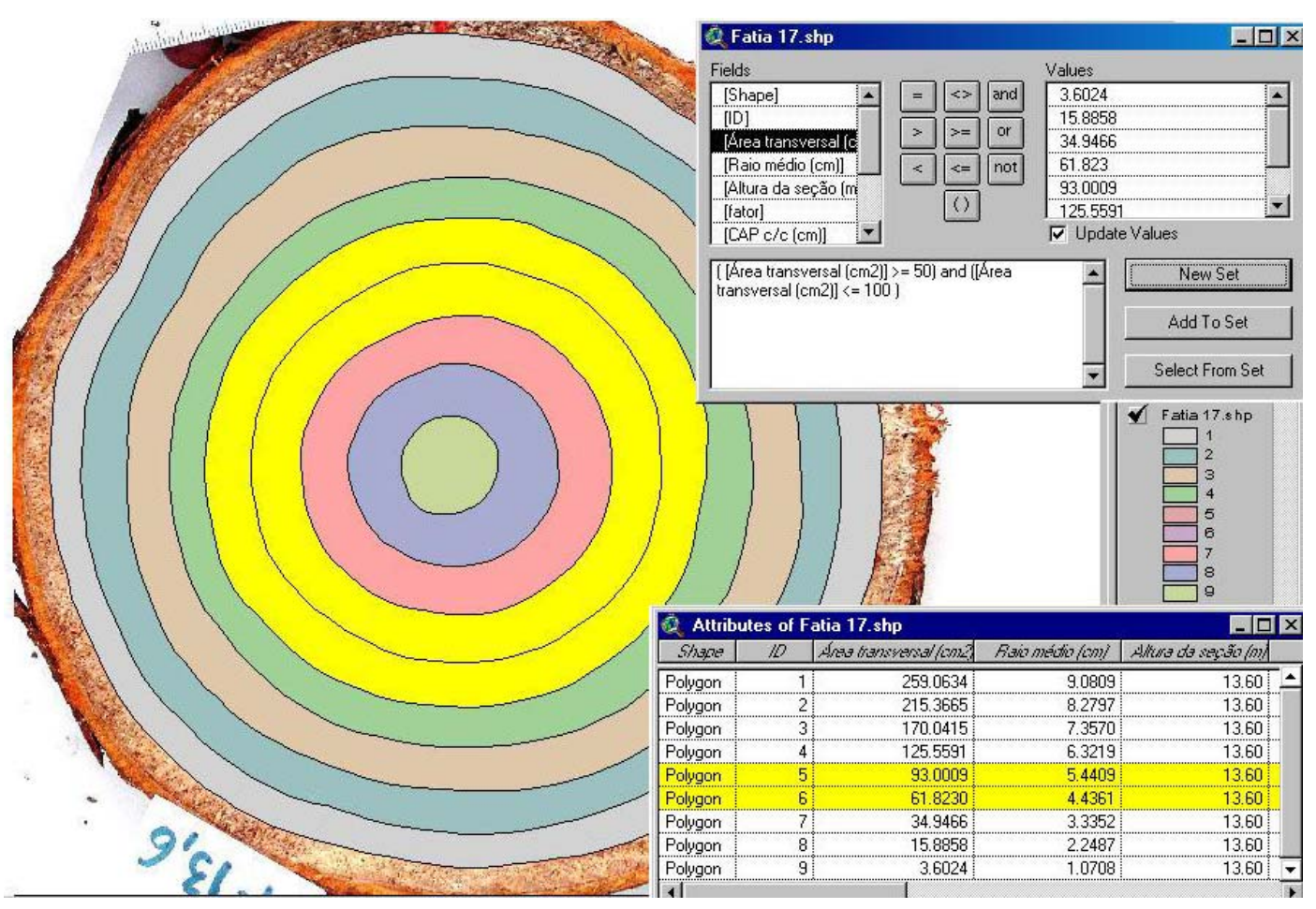

Figura 7: Tela do software ArcView mostrando representação por valor exclusivo e expressão de consulta por atributo

Figure 7: ArcView's window showing the display by unique value and an expression of the selection by attribute

Utilizando o comando "Calculate" (calcular) também foi possível calcular, para cada fatia, a idade da árvore associada a cada anel usando a seguinte expressão:

$[$ Idade $]=17-[\mathrm{ID}]+1$

em que:

$17=$ idade total da árvore utilizada na ANATRO

[ID] = coluna contendo a identificação dos anéis, numerados em ordem crescente da casca para a medula

Para a fatia 4 , tomada a $1,30 \mathrm{~m}$ de altura no fuste, o incremento médio anual (IMA) em diâmetro foi facilmente calculado a partir da multiplicação dos dados da coluna "Raio médio" por 2 e posterior divisão pela coluna "Idade". Os resultados puderam ser visualizados, também, na forma de gráficos (fig. 8), usando-se o menu "Table - Chart" (Tabela - gráfico). 


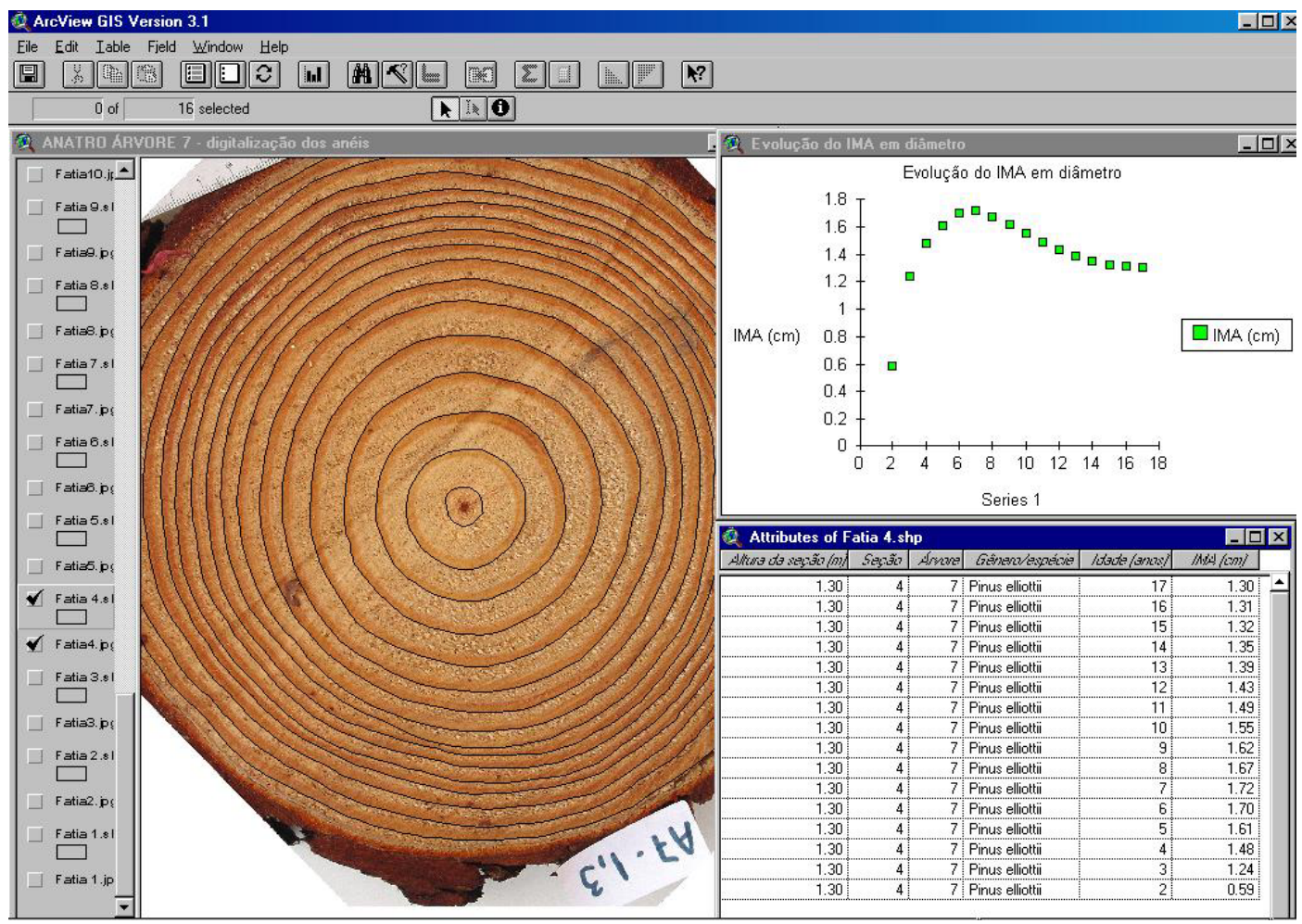

Figura 8; "Vista" do software ArcView contendo a imagem, tabela de atributos e gráfico da evolução do IMA em diâmetro

Figure 8: ArcView's window showing the image of the disc, the attribute table and the graphic of the MAI (dbh) development

O software ArcView (ESRI) mostrou-se bastante adequado em todas as etapas do processamento das áreas transversais. Acredita-se, contudo, que as técnicas aqui descritas podem ser adaptadas para execução em outros software de SIG, como, por exemplo, para o SPRING, que é um software de domínio público e agrega, no mesmo programa, capacidades de processamento digital de imagens e sistemas de informações geográficas.

Uma das principais vantagens da utilização de um SIG na medição de anéis de crescimento é a possibilidade de elaboração de banco de dados, em que as informações espaciais (localização dos anéis na fatia) são associadas aos atributos alfa-numéricos (identificação e características dos anéis, das fatias, das árvores e do povoamento; áreas transversais; raios médios; incrementos radiais, etc). Os SIGs, por definição, são sistemas capazes de armazenar, manipular, atualizar e recuperar essas informações, inclusive adequando-as a outros tipos de processamento, como ocorreu com as áreas transversais, utilizadas para cálculos posteriores na ANATRO.

\section{Análise quantitativa}

A primeira comparação entre os resultados da ANATRO efetuada em ambiente de geoprocessamento (digital) e aqueles obtidos pela ANATRO convencional (manual) foi relativa ao número de anéis de crescimento detectados por um e por outro método (tab. 1). 
Tabela 1: Número de anéis por fatia na anatro digital e anatro manual

Table 1 Number of rings per disc in digital and manual stem analysis

\begin{tabular}{|c|c|c|c|}
\hline \multirow{2}{*}{ FATIA } & \multirow{2}{*}{ ALTURA (m) } & \multicolumn{2}{|c|}{ NÚMERO DE ANÉIS } \\
\hline & & Manual & Digital \\
\hline 1 & 0,00 & 17 & 17 \\
\hline 2 & 0,30 & 17 & 17 \\
\hline 3 & 0,70 & 17 & 17 \\
\hline 4 & 1,30 & 16 & 16 \\
\hline 5 & 2,00 & 15 & 15 \\
\hline 6 & 2,70 & 15 & 15 \\
\hline 7 & 3,70 & 15 & 14 \\
\hline 8 & 4,60 & 14 & 14 \\
\hline 9 & 5,60 & 14 & 13 \\
\hline 10 & 6,70 & 13 & 13 \\
\hline 11 & 7,70 & 12 & 12 \\
\hline 12 & 8,70 & 12 & 12 \\
\hline 13 & 9,70 & 11 & 11 \\
\hline 14 & 10,70 & 11 & 11 \\
\hline 15 & 11,80 & 10 & 10 \\
\hline 16 & 12,70 & 10 & 10 \\
\hline 17 & 13,60 & 9 & 9 \\
\hline 18 & 14,70 & 8 & 8 \\
\hline 19 & 15,70 & 8 & 8 \\
\hline 20 & 16,70 & 7 & 7 \\
\hline 21 & 17,70 & 6 & 6 \\
\hline 22 & 18,50 & 6 & 6 \\
\hline 23 & 19,60 & 5 & 5 \\
\hline 24 & 20,60 & 4 & 4 \\
\hline 25 & 21,70 & 3 & 3 \\
\hline 26 & 22,90 & 3 & 2 \\
\hline 27 & 23,90 & 2 & 2 \\
\hline 28 & 24,90 & 2 & 1 \\
\hline 29 & 25,70 & 1 & 0 \\
\hline 30 & 26,40 & 0 & 0 \\
\hline
\end{tabular}

Apenas em cinco das trinta fatias houve diferença entre o número de anéis e essa diferença não excedeu a uma unidade. $\mathrm{O}$ anel que não se conseguiu detectar na imagem digital foi sempre aquele mais próximo à medula. Também nas fatias secas e lixadas foi difícil localizar os anéis mais internos, porém, nesses casos, recorreu-se ao exame da face inferior, não-lixada da fatia. No total, foram detectados 283 anéis pelo método de medição convencional contra 278 anéis pelo método digital.

Em função dos diferentes valores dos raios médios obtidos pelos métodos manual e digital, também as estimativas das alturas totais a cada idade apresentaram valores diversos para um e outro método. As duas séries de dados encontram-se listadas na Tabela 2. 
Análise de tronco digital...

Tabela 2: Alturas obtidas a partir de anatro manual e digital

Table 2: $\quad$ Total heights estimated in digital and manual stem analysis

\begin{tabular}{c|c|c}
\hline \multirow{2}{*}{ IDADE } & \multicolumn{2}{|c}{ ALTURA TOTAL (m) } \\
\cline { 2 - 3 } & Manual & Digital \\
\hline 1 & 1,04 & 1,21 \\
2 & 2,00 & 2,30 \\
3 & 4,60 & 3,87 \\
4 & 6,51 & 5,91 \\
5 & 7,65 & 7,86 \\
6 & 9,70 & 10,19 \\
7 & 11,80 & 12,09 \\
8 & 13,18 & 13,21 \\
9 & 14,70 & 15,20 \\
10 & 16,66 & 16,84 \\
11 & 17,70 & 18,00 \\
12 & 19,22 & 19,40 \\
13 & 20,60 & 20,90 \\
14 & 21,70 & 22,03 \\
15 & 23,90 & 23,33 \\
16 & 25,70 & 25,22 \\
17 & 26,40 & 26,66 \\
\hline
\end{tabular}

Um teste $\mathrm{t}$ para amostras emparelhadas não detectou diferenças significativas entre as duas séries de dados para um nível de significância $\alpha=0,05$. No gráfico apresentado na Figura 9 observa-se quão próximas estão as alturas totais a cada idade estimadas a partir de dados oriundos da ANATRO manual e da ANATRO digital.

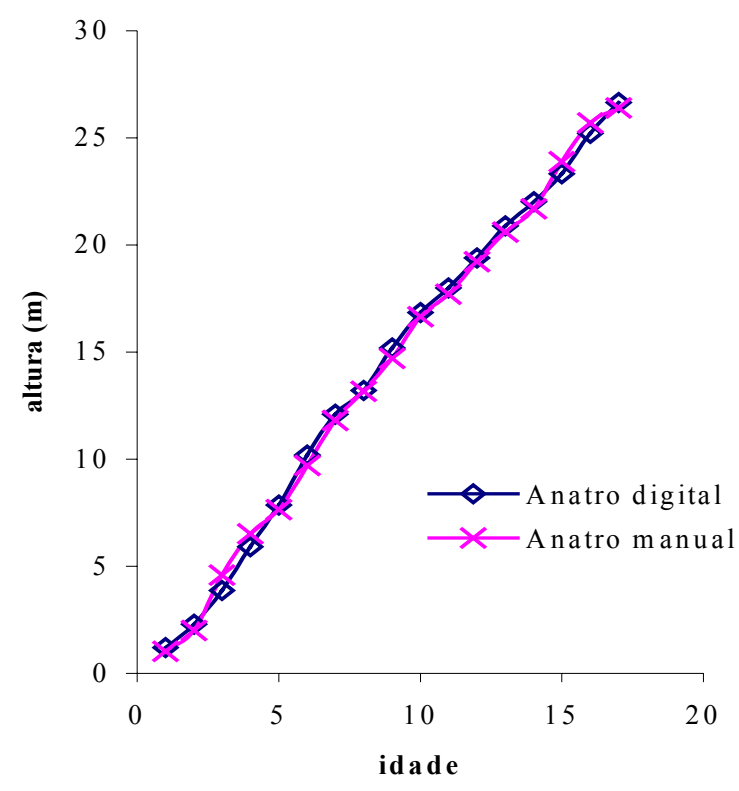

Figura 9: Curva de altura sobre idade com dados de anatro digital e anatro manual Figure 9: Heigth-age curve based on digital and manual stem analysis data 
Os perfis da árvore - construídos a partir das séries de dados de ANATRO digital e manual - são apresentados nas Figuras 10 (a) e 10 (b), respectivamente.

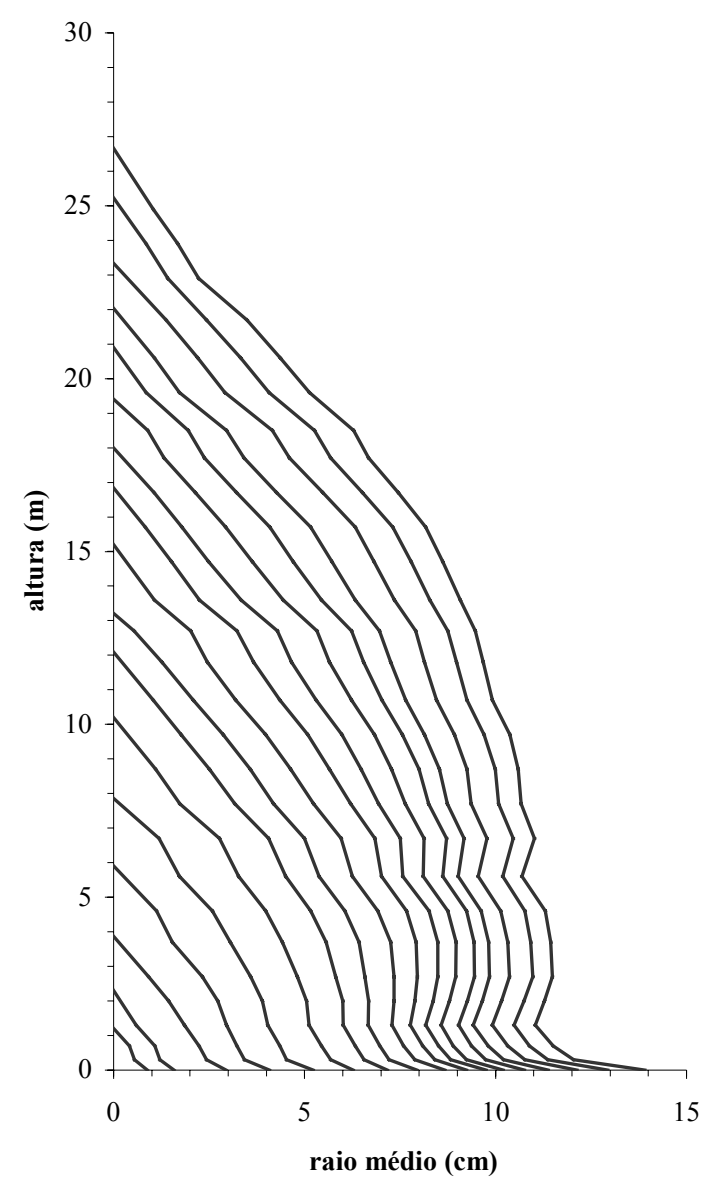

(a)

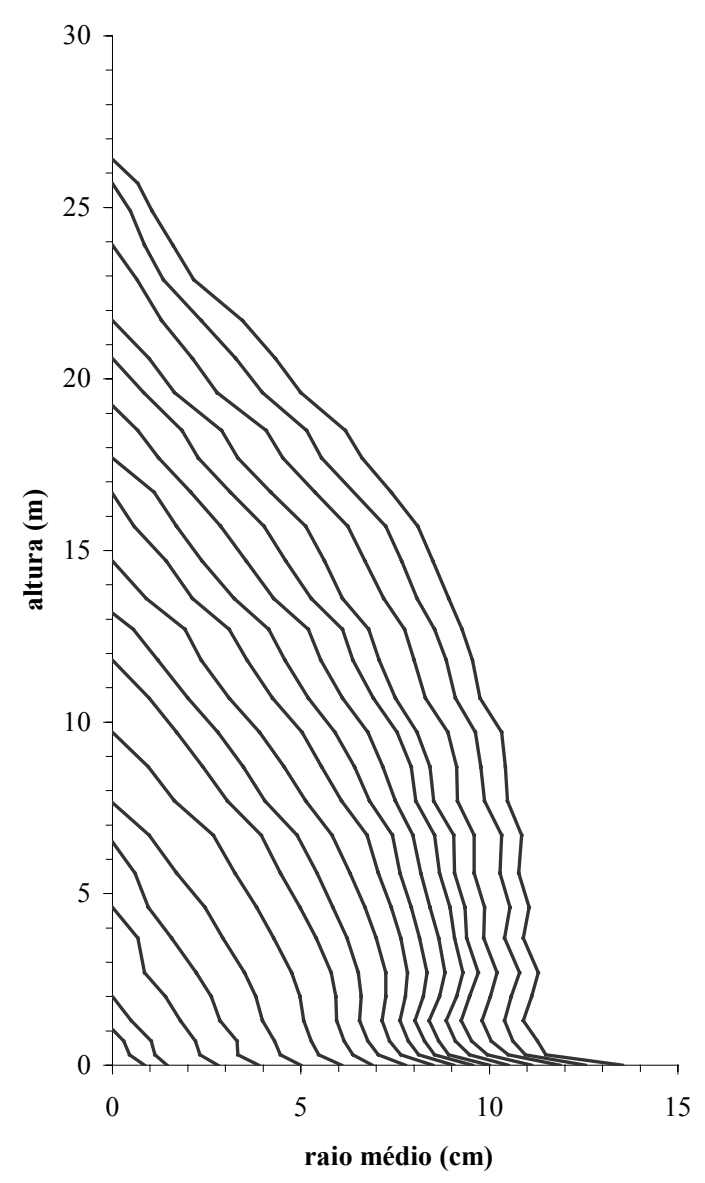

(b)

Figura 10: Perfis da árvore obtidos por ANATRO digital (a) e ANATRO manual (b)

Figure 10: Stem profile for digital (a) and manual (b) stem analysis

Em ambos os perfis se observam nitidamente as mudanças na forma do fuste descritas por Assmann (1970): de neilóide para parabolóide, a cerca de 1,30 metros de altura e, depois, a aproximadamente 23 metros, de parabolóide cúbico para cone. Percebe-se, também, que, de uma maneira geral, o perfil dessa árvore na ANATRO digital apresenta linhas mais suavizadas, arredondadas e mudanças menos abruptas ao longo do fuste quando comparado com o da ANATRO manual. Possivelmente, isso se deve à diferente forma de medição das áreas transversais empregada nos métodos. A ANATRO digital utiliza a completa delimitação do anel e o raio médio considerado para a elaboração do perfil é calculado a partir da área transversal, o que, de certa forma, minimiza as variações individuais entre e dentro das seções.

Os volumes por idade (fig. $11 \mathrm{e} \mathrm{tab.}$ 3) estimados a partir das duas séries de dados (digital e manual) também foram comparados através de um teste $t$ para amostras emparelhadas, que revelou haver diferenças significativas entre eles a um nível de confiança de 95\%. A diferença média percentual absoluta entre os volumes estimados por ANATRO manual e digital foi igual a $7 \%$. 
Análise de tronco digital...

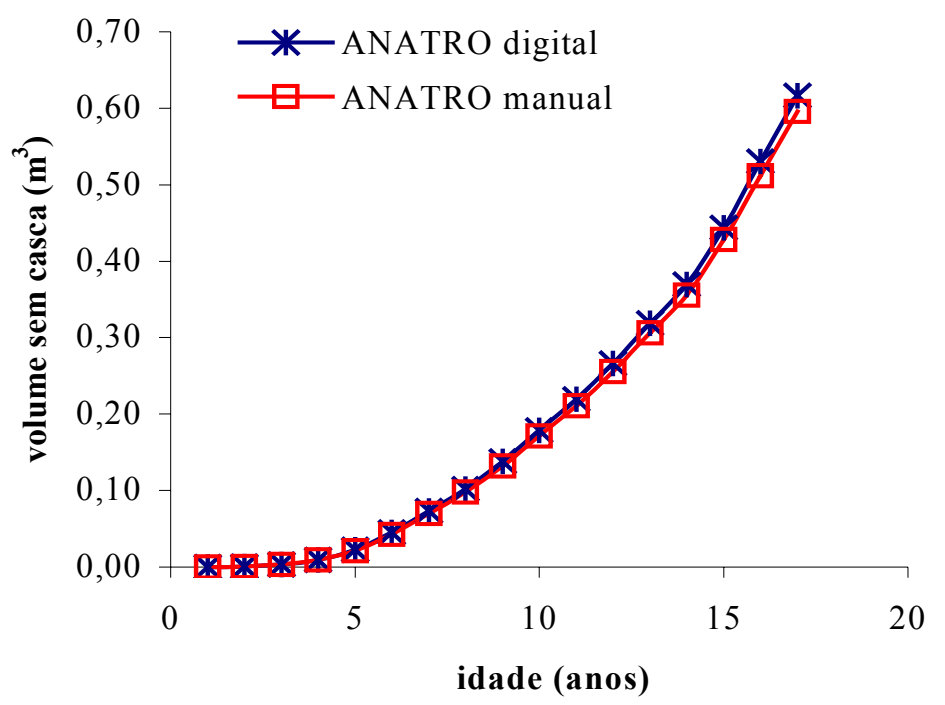

Figura 11: Volumes por idade estimados a partir de dados de anatro manual e digital Figure 11: Estimated volumes per age based on digital and manual stem analysis data

Tabela 3: Volumes por idade estimados a partir de dados de anatro manual e digital Table 3: Estimated volumes per age based on digital and manual stem analysis data

\begin{tabular}{c|c|c}
\hline \multirow{2}{*}{ IDADE } & \multicolumn{2}{|c}{ VOLUME TOTAL SEM CASCA $\left.\mathbf{~ m}^{3}\right)$} \\
\cline { 2 - 3 } 2 & 0,0000652 & \multicolumn{1}{c}{ Digital } \\
\hline 3 & 0,0004452 & 0,0000898 \\
4 & 0,0031242 & 0,0005313 \\
5 & 0,0092303 & 0,0032098 \\
6 & 0,0214903 & 0,0096097 \\
7 & 0,0428904 & 0,0228155 \\
8 & 0,0702533 & 0,0451057 \\
9 & 0,0978647 & 0,0735072 \\
10 & 0,1323609 & 0,1018369 \\
11 & 0,1716171 & 0,1382406 \\
12 & 0,2110175 & 0,1791090 \\
13 & 0,2556577 & 0,2197424 \\
14 & 0,3065571 & 0,2662753 \\
15 & 0,3556391 & 0,3188638 \\
16 & 0,4280997 & 0,3699569 \\
17 & 0,5115830 & 0,4438381 \\
\hline & 0,5961613 & 0,5304838 \\
\hline \multirow{2}{*}{1} & & 0,6165403 \\
\hline
\end{tabular}


Enquanto o método tradicional expressa o volume seco da árvore, a ANATRO digital obtém resultados relativos a diâmetros, áreas transversais e volumes "verdes", que são efetivamente encontrados quando por ocasião da medição de árvores na floresta e refletem, portanto, situações mais próximas da realidade.

\section{CONCLUSÕES}

A obtenção de áreas transversais para a ANATRO completa de uma árvore de Pinus elliotti com 17 anos foi efetuada com sucesso em ambiente de geoprocessamento e representa uma alternativa viável em substituição aos procedimentos tradicionais.

O emprego de técnicas fotográficas nos procedimentos de análise de tronco tem como vantagem principal a eliminação da necessidade do transporte das fatias ao laboratório, secagem, aplicação de lixas e redução do espaço físico para armazenamento das fatias

A utilização de SIGs na medição de anéis de crescimento e a conseqüente elaboração de um banco de dados permite a associação de informações espaciais (localização dos anéis na fatia) a atributos alfa-numéricos (identificação e características dos anéis, das fatias, das árvores e do povoamento; valores das áreas transversais; raios médios; incrementos radiais, etc.). O software ArcView (ESRI) usado na pesquisa mostrou-se bastante adequado em todas as etapas do processamento para obtenção de áreas transversais.

O uso da técnica de medição digital de anéis de crescimento em empresas florestais está condicionado ao grau de envolvimento dos profissionais ligados à engenharia florestal com a operacionalização do sistema e também a uma política interna que promova a descentralização do SIG e a difusão de seu uso.

\footnotetext{
A diferença percentual (7\%) entre volumes estimados por medição convencional (volume após secagem) e a partir de fotos digitais deve-se, em grande
}

parte, à condição verde e, portanto, úmida, da fatia fotografada ainda no campo.

A utilização da câmera digital representa, certamente, um avanço tecnológico importante na aquisição de imagens das fatias e reflete uma tendência mundial em termos de tratamento digital da informação.

\section{REFERÊNCIAS}

ASSMANN, E. The principles of forest yield study. Oxford: Pergamon Press, $1970.506 \mathrm{p}$.

AVERY, T. E.; BERLIN, G. L. Fundamentals of remote sensing and airphoto interpretation. 5. ed. Upper Saddle River: Prentice Hall, 1992. 472 p.

BARUSSO, A. P. Determinação de funções de crescimento mediante análise de tronco. Curitiba, 1977. 133 f. Dissertação (Mestrado em Engenharia Florestal) - Setor de Ciências Agrárias, Universidade Federal do Paraná. Não defendida.

BIGING, G. S.; WENSEL, L. C. A photographic technique for use with stem analysis. Forest Science, Bethesda, v. 30, p. 715-729, 1984.

CAMPBELL, J. B. Introduction to remote sensing. 2. ed. New York: The Guilford Press, 1996. $622 \mathrm{p}$.

CRÓSTA, A. P. Processamento digital de imagens de sensoriamento remoto. Campinas: IG, 1993. 170 p.

DISPERATI, A. A.; BERNARDI, D.; KNAPP, A. K. Avaliação de imagens da câmara digital $35 \mathrm{~mm}$ KODAK DCS 420 CIR. Floresta, Curitiba, v. 27, n. 1/2, p. 1724, 2000.

GOELZ, J. C. G.; BURK, T. E. Testing a photographic method for measuring stem cross-sections. Forest Science, Bethesda, v. 33, n. 3, p. 784-789, 1987.

HUSCH, B.; MILLER, C. I.; BEERS, T. W. Forest mensuration. New York: Ronald Press Co., 1982. 410 p. 
JENSEN, J. R. Introductory digital image processing. 2. ed. Upper Saddle River: Prentice Hall, 1996. 318 p.

LILLESAND, T. M.; KIEFER, R. W. Remote sensing and image interpretation. 3. ed. Crawfordsville: J. Wiley and Sons, 1994. $750 \mathrm{p}$.

MARQUES FILHO, O.; VIEIRA NETO, H. Processamento digital de imagens. Rio de Janeiro: Brasport, 1999. 411 p.

MOREIRA, M. A. Fundamentos do sensoriamento remoto e metodologias de aplicação. São José dos Campos: INPE, 2001. 250 p.

NAGEL, J.; ATHARI, S. Stammanalyse und ihre Durchführung. Allgemeine Forstund Jagdzeitung, Frankfurt am Main, v. 153, n. 9/10, p. 179-182, 1982.

RIGOZO, N. R.; NORDEMANN, D. J. R. Tree-ring image interactive treatment. São José dos Campos: [s.n.], 2000. Não publicado.

ROSOT, M. A. D.; FIGUEIREDO FILHO, A.; DISPERATI, A. A. Medição de anéis de crescimento através de técnicas de análise de imagem. In: SEMINÁRIO DE ATUALIZAÇÃO EM SENSORIAMENTO REMOTO E SISTEMAS DE INFORMAÇÕES GEOGRÁFICAS APLICADOS À ENGENHARIA FLORESTAL, 4., 2000, Curitiba. Anais ... Curitiba: FUPEF, 2000. p. 197-198.

ROSOT, M. A. D.; DISPERATI, A. A.; FIGUEIREDO FILHO, A. F. Medição da área de anéis de crescimento usando imagens digitais. Revista Árvore, Viçosa, v. 25 , n. 1, p. 79-88, 2001.

\section{SENAGRO}

SENSORIAMENTO REMOTO. Curso básico de ARCVIEW 3.1 e 3.2A. Curitiba, 2002. Apostila de treinamento.

TASISSA, G.; BURKHART, H. E. Modeling thinning effects on ring width distribution in loblolly pine (Pinus taeda). Canadian Journal of Forest Research, Toronto, v. 27, p. 1291-1301, 1997.

THETFORD, R. D; D'ARRIGO, R. D.; JACOBY, G. C. An image analysis system for determining densitometric and ringwidth time series. Canadian Journal of Forest Research, Toronto, v. 21, p. 15441549, 1991.

TUCKER, C. C.; CHAKRABORTY, S. Quantitative assessment of lesion characteristics and disease severity using digital image processing. Journal of Phytopathology, Berlin, v. 145, p. 273278, 1997. (Special Report, 10).

WERKEMA, M. C. C. Como estabelecer conclusões com confiança: entendendo inferência estatística. Belo Horizonte: Fundação Christiano Ottoni, 1996. 279 p.

YANOSKY, T. M.; ROBINOVE, C. J. Digital image measurement of the area and anatomical structure of tree rings. Canadian Journal of Botany, Ottawa, v. 64, p. 2896-2902, 1986 